\title{
Spatial patterns of coral survivorship: Impacts of adult proximity versus other drivers of localized mortality
}

David A Gibbs, Mark E Hay

Species-specific enemies may promote prey coexistence through negative distance- and density-dependent survival of juveniles near conspecific adults. We tested this mechanism by transplanting juvenile-sized fragments of the brooding corals Pocillopora damicornis and Seriatopora hystrix 3, 12, 24 and $182 \mathrm{~cm}$ up- and down-current of conspecific adults and monitoring their survival and condition over time. We also characterized the spatial distribution of $P$. damicornis and $S$. hystrix within replicate plots on three Fijian reef flats and measured the distribution of small colonies within $2 \mathrm{~m}$ of larger colonies of each species. Juvenile-sized transplants exhibited no differences in survivorship as a function of distance from adult $P$. damicornis or $S$. hystrix. Additionally, both P. damicornis and $S$. hystrix were aggregated rather than overdispersed on natural reefs. However, a pattern of juveniles being aggregated near adults while larger (and probably older) colonies were not suggests that greater mortality near large adults could occur over longer periods of time or that size-dependent mortality was occurring. While we found minimal evidence of greater mortality of small colonies near adult conspecifics in our transplant experiments, we did document hot-spots of species-specific corallivory. We detected spatially localized and temporally persistent predation on $P$. damicornis by the territorial triggerfish Balistapus undulatus. This patchy predation did not occur for $S$. hystrix. This variable selective regime in an otherwise more uniform environment could be one mechanism maintaining diversity of corals on Indo-Pacific reefs. 
Spatial patterns of coral survivorship: Impacts of adult proximity versus other drivers of localized mortality

David A. Gibbs, School of Biology, Georgia Institute of Technology, Atlanta, GA, USA Mark E. Hay, School of Biology and Aquatic Chemical Ecology Center, Georgia Institute of Technology, Atlanta, GA, USA*

* Corresponding Author: 310 Ferst Drive, Atlanta, GA 30332, USA mark.hay@biology.gatech.edu, 404-894-8429

\section{Abstract}

Species-specific enemies may promote prey coexistence through negative distance- and density-dependent survival of juveniles near conspecific adults. We tested this mechanism by transplanting juvenile-sized fragments of the brooding corals Pocillopora damicornis and Seriatopora hystrix 3, 12, 24 and $182 \mathrm{~cm}$ up- and down-current of conspecific adults and monitoring their survival and condition over time. We also characterized the spatial distribution of $P$. damicornis and $S$. hystrix within replicate plots on three Fijian reef flats and measured the distribution of small colonies within $2 \mathrm{~m}$ of larger colonies of each species. Juvenile-sized transplants exhibited no differences in survivorship as a function of distance from adult $P$. damicornis or S. hystrix. Additionally, both P. damicornis and S. hystrix were aggregated rather than overdispersed on natural reefs. However, a pattern of juveniles being aggregated near adults while larger (and probably older) colonies were not suggests that greater mortality near large adults could occur over longer periods of time or that size-dependent mortality was occurring. While we found minimal evidence of greater mortality of small colonies near adult conspecifics in our transplant experiments, we did document hot-spots of species-specific corallivory. We detected spatially localized and temporally persistent predation on P. damicornis by the territorial triggerfish Balistapus undulatus. This patchy predation did not occur for S. hystrix. This variable selective regime in an otherwise more uniform environment could be one mechanism maintaining diversity of corals on Indo-Pacific reefs. 


\section{Introduction}

The processes maintaining high numbers of species in tropical rainforests and coral reefs have long been investigated (Connell 1978). One suggested mechanism for maintaining diversity is the Janzen-Connell hypothesis (Janzen 1970; Connell 1971), which proposes that speciesspecific enemies clustered near adults increase the local mortality of conspecific juveniles and prevent any single species from monopolizing resources. It has generally been applied to longlived, stationary, terrestrial organisms such as trees (Zhu et al. 2013). Although there are examples of species-specific distance- or density-dependent mortality affecting community species richness (e.g., Packer and Clay 2000; Petermann et al. 2008; Bagchi et al. 2014), a metaanalysis found no general, net effect of distance from parent on offspring mortality across a variety of plant types, habitats, or life stages (Hyatt et al. 2003). Thus, some tree species may experience Janzen-Connell effects (Johnson et al. 2012) but the generality of the pattern has been difficult to document (Hyatt et al. 2003). In part, this may be because numerous other processes (habitat heterogeneity, spatial patterns of competitors, etc.) could obscure Janzen-Connell effects. This makes experimental tests difficult in field settings, especially when spatial scales over which they may be relevant are unclear.

Research addressing Janzen-Connell effects on coral reefs is rare (Marhaver et al. 2013). Explanations for maintenance of coral diversity more often invoke disturbance regimes, abiotic gradients (e.g., light, sedimentation), and competition hierarchies (Lang 1973; Connell 1978;

Buss and Jackson 1979; Porter et al. 1981). One reason for the paucity of tests in marine systems may be that the hypothesis assumes that dispersal decreases monotonically with distance from parents and that the average dispersal distance is greater than the average distance from the parent at which predation occurs but that they are on the same order of magnitude (Nathan and 
51 Casagrandi 2004), neither of which necessarily applies to marine species with pelagic larvae.

52 Coral larvae are competent to settle within hours of release to months after release (Richmond 1987; Miller and Mundy 2003; Nozawa and Harrison 2008) and may disperse up to hundreds of

54 kilometers (Jones et al. 2009; Torda et al. 2013). Therefore, unlike seeds of many tree species, coral larvae need not be distributed as "seed shadows" with juveniles clustered near parents.

Nevertheless, distance- or density-dependent mortality of juveniles could affect coral species employing either of the sexual reproduction methods that corals use: broadcast spawning, in which eggs and sperm are released into the water column and fertilized eggs develop outside corals, or brooding, in which sperm are released into the water column and fertilize eggs retained inside adult coral colonies. Larvae produced by both methods select their settlement sites and can be attracted to the chemical cues of conspecifics (Dixson, Abrego, and Hay 2014); this could lead to larvae settling near conspecific adults or in aggregations (e.g., Dunstan and Johnson 1998). Additionally, brooding corals may cast larval shadows akin to terrestrial seed shadows because larvae from brooding corals frequently settle quickly and close to their parents (Carlon and Olson 1993; Tioho, Tokeshi, and Nojima 2001; Vermeij 2005; Vermeij and Sandin 2008;

66 Torda et al. 2013) specialist enemies that accumulate near adults over their lifetimes. While this may be the case for terrestrial plants where many herbivores and pests are specialists (Bernays 1989), it is unclear to what extent this applies to corals, of which there are relatively few identified species-specific consumers that might be expected to accumulate near adults of specific prey species (Cornell and Karlson 2000; Rotjan and Lewis 2008; but see Neudecker 1979 and Jayewardeen et al. 2009 for examples of coral-specific predation). 
et al. 2014; Fricke, Tewksbury, and Rogers 2014) and marine systems (Marhaver et al. 2013)

that microbial pathogens may accumulate near adults and suppress the survivorship of conspecific recruits or juveniles. In the most direct test of the Janzen-Connell hypothesis in corals, Marhaver et al. (2013) used a series of lab and field investigations in the Caribbean to attribute higher mortality of Orbicella (formerly Montastraea) faveolata recruits placed near adult conspecifics to adult-associated microbial enemies. They found a complex relationship between distance from adult colonies, current direction, and recruit mortality. In less direct tests, Vermeij (2005) and Vermeij and Sandin (2008) observed that survival of coral recruits decreased with increasing cover of conspecifics; they hypothesized that this was due to species-specific microorganisms rather than to saturation of a limiting resource.

No study has explicitly tested the Janzen-Connell hypothesis in brooding corals or in fragments typical of juvenile-sized corals. These conditions may generate different results from previously tested conditions because brooding corals may be subject to different distancedependent mortality patterns compared to broadcast spawning corals and because small fragments may differ from newly settled larvae. For instance, distance-dependent mortality is known to affect some seedlings more than seeds in terrestrial systems (Hyatt et al. 2003). We experimentally evaluated distance-dependent mortality of juvenile-sized corals in the field and correlatively surveyed multiple reefs for patterns of spatial distribution suggestive of JanzenConnell effects. We focused on two brooding coral species (Seriatopora hystrix and Pocillopora damicornis) whose planulae recruit over short distances, the latter of which is known to be a preferred prey for some coral consumers (Neudecker 1979). 
97

98

99

100

101

102

103

104

105

106

107

108

109

110

111

112

113

114

115

116

117

118

\section{Methods}

\section{Study site characteristics}

This study was conducted on reef flats within no-take marine protected areas (MPAs) adjacent to Votua, Vatu-o-lailai, and Namada villages along the Coral Coast of Viti Levu, Fiji. These reserves are scattered along $11 \mathrm{~km}$ of fringing reef and are separated by $\sim 3-8 \mathrm{~km}$. The reserves have high coral cover (38-56\%), low macroalgal cover (1-3\%), and a high biomass and diversity of herbivorous fishes (Rasher, Hoey, and Hay 2013; Bonaldo and Hay 2014). The reef flats range from $\sim 1-3 \mathrm{~m}$ deep at high tide, exposed to $\sim 1.5 \mathrm{~m}$ deep at low tide, extend $\sim 500-600$ $\mathrm{m}$ from shore to the reef crest, and are typical of exposed reef flats occurring throughout Fjii.

Except during low tides in calm weather, waves push water over the reef front, and water then flows laterally across the reef flats to discharge through channels bisecting the flats. This creates a relatively predictable current direction at most locations.

\section{Survival experiments}

To test whether juvenile corals experienced distance-dependent mortality near adult conspecifics, we created $\sim 5 \mathrm{~mm}$ tall fragments of $P$. damicornis and $S$. hystrix, selected suitable adult focal colonies (defined below), attached conspecific fragments 3, 12, 24 and $182 \mathrm{~cm}$ upand down-current from each focal adult, and monitored fragment survival. General direction of current (east to west) was determined by in-water observations over $\sim 7$ years of working at this site. We conducted this experiment in Votua village's MPA, which supports a diverse assemblage of corals covering about $50 \%$ of hard substrates (Rasher, Hoey, and Hay 2013). Water flow across this reef flat is often negligible around low tide, reducing the potential for constantly dissipating microbial enemies away from focal colonies. 
121 fragments from older colonies as proxies for $\sim 6$ month old juveniles (Sato 1985) because, despite

122 these species reproducing monthly in some locations (Fan et al. 2002; Kuanui et al. 2008), neither species planulated at our site during the months of this study (August through October 2013). The fragments from each of four source colonies for a species were collected in six rounds over two days. Each round was taken to shore and four fragments (one from each source colony) were epoxied (Emerkit epoxy) onto the unglazed side of 162.54 x $2.54 \mathrm{~cm}$ tiles. Thus, each tile had fragments from four different colonies and sets of 16 tiles had fragments from the same four colonies of the same species. After epoxying, tiles were held in a tub of seawater for $\sim 1 \mathrm{~h}$, allowing the epoxy to harden. Tiles were then cable-tied onto metal racks at $\sim 1 \mathrm{~m}$ deep in the MPA and allowed to acclimate for two weeks before deployment in the experiment. Survivorship during acclimation was $100 \%$, producing 384 fragments on 96 tiles for each coral species.

Within the MPA, 10 adult $P$. damicornis and 10 adult $S$. hystrix colonies served as focal colonies. Focal colonies: i) were $>10 \mathrm{~cm}$ at their smallest diameter (10 to $35 \mathrm{~cm}$ for $P$. to confound effects of the focal colony with effects of nearby conspecifics), iii) were $5-40 \mathrm{~cm}$ deep at low tide, and iv) had space for $190 \mathrm{~cm}$ PVC pipes to be placed roughly east and west (the predominant current direction was west) without disturbing other corals. Focal colonies were photographed from above and their size determined using ImageJ (Rasband 1997). 
142 and cementing the rebar to the pipe. Notches $2.54 \mathrm{~cm}$ long allowed us to cable-tie tiles onto the 143 pipes at distances of 3, 12, 24 and $182 \mathrm{~cm}$ from focal colonies (Fig 1a, 1b). This approach

144 secured all pipes and tiles throughout the experiment. These distances and this scale were chosen 145 to match a previous experiment in the Caribbean that had detected distance-dependent mortality 146 of newly settled recruits for a broadcast spawning coral (Marhaver et al. 2013).

Tiles were randomly assigned to positions on pipes. Thus, fragments at each distance and around each conspecific focal colony were random with respect to source colony. Unassigned tiles were kept on the rack as spares (64 fragments on 16 tiles for each coral species).

Every 1-2 d after deployment, we examined all fragments, recording survivorship, consumption, overgrowth by algae, bleaching, or other changes in status. The $P$. damicornis fragments were observed for 59 days. The $S$. hystrix fragments were deployed one month later and observed for 29 days.

On some $P$. damicornis tiles, three or four of the fragments disappeared within a $24 \mathrm{~h}$ period between checks on their condition, appearing to have been bitten off. To determine the agents of this localized mortality, we replaced tiles whose four fragments had been eaten with spare tiles holding four healthy fragments around three of the focal colonies that had experienced localized mortality and videotaped the tiles (GoPro II HD) from about $1 \mathrm{~m}$ away during the following high tides. Cameras were retrieved at the next low tide and the videos watched. We evaluated overall survival patterns and mortality specifically due to bleaching or predation using mixed-effects Cox proportional hazards survival models (coxme package, Therneau 2012) in R (R Core Team 2013). Distance and direction from focal colony were fixed effects (4 levels and 2 levels, respectively) and focal colony and tile nested within focal colony were random effects because fragments were blocked by tile and focal colony. The size of the 
165 focal colony and the depth of the tiles were included as covariates. Finally, we compared the

166 relative levels of predation and bleaching in $P$. damicornis and S. hystrix using a chi-square test.

167

168 Distribution surveys

169 We characterized the spatial distribution of $P$. damicornis and S. hystrix in the reef flat

170 MPAs of Namada, Vatu-o-lailai, and Votua villages at two scales (August through October

171 2013). For the larger-scale survey, we mapped each colony within $8 \times 8 \mathrm{~m}$ plots $(\mathrm{N}=5$, 5, and 10

172 for Namada, Vatu-o-lailai, and Votua, respectively). Each plot was divided into 2560.5 x $0.5 \mathrm{~m}$

173 cells and each coral $\geq 1 \mathrm{~cm}$ across mapped into a cell. The location of each survey plot was

174 determined by randomly choosing a point on shore, swimming 100, 200, or 300 kicks directly

175 away from shore at that point, and surveying the closest bommie (coral patch) large enough to

176 fill more than three quarters of an $8 \times 8 \mathrm{~m}$ plot. In four of 10 surveys at Votua and in all five

177 surveys at Vatu-o-lailai and Namada, we also measured the largest diameter of each $P$.

178 damicornis colony. We did not measure $S$. hystrix colony size because the frequent discontinuity

179 of colonies made accurate estimation of colony area too error-prone. To avoid confounding

180 biotically-driven spatial distribution with patterns caused by patchiness of suitable substrate, we

181 also recorded which cells were comprised primarily of unsuitable habitats such as sand-scoured

182 pools or channels and bommie tops covered in rubble.

We analyzed these data using the neighborhood density function $\mathrm{O}(\mathrm{r})$ in the point pattern

analysis program Programita (Wiegand and Moloney 2004). This analysis identifies distances at

which individuals are aggregated, randomly spaced, or overdispersed compared to a specified

186

null model. Unlike the more frequently used Ripley’s K(r) statistic, each distance category is not

187 affected by those inside it; expected aggregation at each distance is compared to the observed 
188 value independently of nearer distances. Each concentric ring centered on an individual coral is 189 separately placed on the aggregated-overdispersed continuum and displays the spatial pattern 190 within a different distance category. Ring width was $0.5 \mathrm{~m}$ extending up to $4 \mathrm{~m}$. The null model

191 for this analysis was complete spatial randomness (CSR). Because the variance in substrate types 192 violated CSR's assumption of uniform likelihood of coral placement, we conducted the below 193 analyses once using the entirety of all $8 \times 8 \mathrm{~m}$ plots and a second time excluding cells of 194 unsuitable habitat (which should better meet CSR's assumption of uniform likelihood).

To determine whether the observed spatial pattern was random, significantly aggregated, or overdispersed, Programita simulated placement of each plot's colonies 999 times using CSR, calculated $\mathrm{O}(\mathrm{r})$ for each simulation, then combined replicate $\mathrm{O}(\mathrm{r})$ 's from each reef and from all three reefs. This generated a distribution of simulated $\mathrm{O}(\mathrm{r})$ 's from which we established the significance of the observed spatial patterns. The distance(s) at which significant aggregation or overdispersion occurred were determined by the distances at which the observed pattern fell above or below the $95 \%$ simulation envelopes, respectively. This analysis does not parse aggregating and overdispering processes; it shows the net resulting pattern.

In addition to analyzing all $P$. damicornis and $S$. hystrix colonies, we analyzed $P$.

damicornis $<5 \mathrm{~cm}, \geq 5 \mathrm{~cm}, \geq 10 \mathrm{~cm}$, and $\geq 15 \mathrm{~cm}$ in diameter to see if spatial patterns changed with colony size. The $<5 \mathrm{~cm}$ and $\geq 5 \mathrm{~cm}$ categories were mutually exclusive but because there were not enough colonies between 5 and $10 \mathrm{~cm}$ and between 10 and $15 \mathrm{~cm}$ to analyze as mutually exclusive groups, larger size categories were subsets of smaller ones.

The $8 \times 8$ m quadrat surveys could not resolve spatial patterns below the cell size of $0.5 \times$ $0.5 \mathrm{~m}$, meaning that patterns occurring at less than $0.25^{2} \mathrm{~m}$ could be undocumented. To

210 determine the spatial distribution of $P$. damicornis and S. hystrix at smaller scales, we conducted 
$2112 \mathrm{~m}$ radius circular surveys around focal $P$. damicornis and $S$. hystrix colonies that i) were the

212 largest colony of that species within $4 \mathrm{~m}$ (to reduce the effects of conspecifics), and ii) occurred

213 where $>75 \%$ of the substrate within $2 \mathrm{~m}$ was suitable habitat for P. damicornis and S. hystrix,

214 again to equalize the likelihood of colonies occurring everywhere in the survey.

215 The distance to each surrounding (radial) $P$. damicornis and S. hystrix colony was the

216 average of the distance to that colony's near and far sides $(\mathrm{N}=45$ focal colonies for $P$. damicornis

217 around $P$. damicornis, 10 for $S$. hystrix around P. damicornis, and 24 each for P. damicornis and

$218 S$. hystrix around $S$. hystrix). We analyzed radial colony counts in $10 \mathrm{~cm}$ concentric rings using a

219 generalized linear mixed effects model with Poisson errors and the canonical log link function in

220 R (lme4 package, Bates et al. 2013). Distance was a fixed effect and focal colony was a random

221 effect, with the $\log _{10}$ of the ring sizes as an offset to control for unequal area sampled at each

222 distance (i.e. ring area increased with distance from the focal colony). We repeated this analysis

223 with just the closest $0.5 \mathrm{~m}$ and $1 \mathrm{~m}$ of the circles in case radial colonies beyond those distances

224 were masking short-range effects of the focal colonies.

We also analyzed the $P$. damicornis data from the $8 \times 8 \mathrm{~m}$ plots in the same manner as we did the circular surveys. To convert the plot data, a function was written in R to identify every surveyed $P$. damicornis colony $\geq 2 \mathrm{~m}$ from all edges of its plot and equal to or larger than a specified diameter (either 15 or $20 \mathrm{~cm}$ ) as a focal colony $(\mathrm{N}=38$ and 19 focal colonies, respectively). In order to have an appreciable sample size, we did not restrict focal colonies to those that were the largest within $4 \mathrm{~m}$. The script then calculated the distances to all $P$. damicornis colonies less than the specified focal colony diameter within $2 \mathrm{~m}$ and placed them into $10 \mathrm{~cm}$ concentric rings as above. We analyzed the resulting data using the same procedures

233 as described for the circular surveys. 


\section{Results}

\section{Survival experiments}

In our field experiment, neither distance nor direction from focal colony significantly

affected survival of $P$. damicornis or $S$. hystrix fragments (Fig. 2a \& b, respectively). We

observed two main categories of mortality: bleaching preceding death in place (potentially due to microbes [e.g., Ben-Haim, Zicherman-Keren, and Rosenberg 2003]) and partial or complete disappearance, putatively due to predation (akin to Lenihan et al. 2011). Bleaching (47 and 46 affected by distance or direction (Fig. 2c \& d). Distance and direction did not affect the number of $P$. damicornis fragments that partially or fully disappeared (putative predation), and direction did not affect this for $S$. hystrix but distance was significant $(\mathrm{z}=2.23, \mathrm{p}=0.03)$ (Fig. 2e \& f), with disappearance increasing with distance from the focal colony. In contrast, $0 \%$ of the 64 extra fragments of each species remaining on the coral rack where we originally acclimated the corals bleached or disappeared despite being on the same reef at the same time (Cox proportional hazards survival analysis, likelihood ratio for $P$. damicornis $=16.5$, likelihood ratio for $S$. hystrix $=24.7, \mathrm{p}<0.0001$ for both species). Fragments on the coral rack were $\sim 1 \mathrm{~m}$ above the benthos and may have experienced more flow or fewer benthic-associated biotic or physical stressors compared to the fragments on PVC pipes, which were 5-15 cm above the benthos. The rapid disappearance of $P$. damicornis fragments around some focal colonies suggested spatially localized predation. Therefore, we further divided deaths due to putative predation between isolated predation incidents (disappearance of one or two fragments on a tile in $24 \mathrm{~h}$ ) and localized predation episodes (disappearance of three or four fragments from a tile in 
$25724 \mathrm{~h}$ ). We used this classification scheme because three or four fragments tended to disappear

258 from multiple tiles within the same $24 \mathrm{~h}$ period at certain replicates, whereas the disappearance

259 of one or two fragments was not often temporally coincident across tiles within a replicate. We

260 distinguished between these two types of putative predation because their causes were potentially

261 different and therefore either one could have been distance-dependent or masked distance-

262 dependence in the other. Six of 10 P. damicornis replicates (23 out of 160 tiles) experienced

263 localized predation on at least one of their eight tiles; three of those experienced localized

264 predation on five or more tiles within $24 \mathrm{~h}$. Two of 10 S. hystrix replicates experienced localized

265 predation (on one tile each). We further investigated localized predation only for $P$. damicornis

266 because localized predation on S. hystrix was infrequent.

267 When tiles that had experienced localized predation around three focal colonies were

268 replaced with spare tiles holding healthy fragments, all three sets of replacement tiles again

269 experienced localized predation and their collective survival was significantly lower than that of

270 the replicates that did not experience localized predation in the initial run (mixed effect Cox

271 proportional hazards, $\mathrm{z}=3.5, \mathrm{p}<0.0005)$. Videos of these tiles showed the territorial triggerfish

272 Balistapus undulatus consuming multiple fragments from multiple tiles around two of the three

273 focal colonies. Balistapus undulatus feeding resulted in fragments irregularly broken at or above

274 the top of the epoxy, as was seen for most localized predation episodes in the initial outplanting.

275 We next examined whether localized predation was distance-dependent and whether it

276 masked distance-dependent mortality in replicates that did not experience localized predation.

277 Distance and direction did not significantly affect mortality in replicates that did not experience

278 localized predation (Fig 3a). Considering only replicates that experienced localized predation 
279 (both original and replacement tiles), neither distance nor direction significantly affected

280 mortality from all causes (Fig. 3b) or just from localized predation (Fig. 3c).

Pocillopora damicornis fragments were significantly more likely to die of putative

282 predation as opposed to bleach and die in place than were $S$. hystrix fragments (chi-square test,

$\left.283 \chi^{2}=17.2, \mathrm{df}=1, \mathrm{p}<0.0001\right)$. More than three times as many $P$. damicornis fragments died from

284 putative predation as bleached prior to death (169 vs. 47 out of 320, respectively), while numbers

285 of $S$. hystrix fragments that died from putative predation versus bleaching did not differ

286 significantly (58 vs. 46 out of 320, respectively). Excluding replicates with localized predation,

$287 P$. damicornis and $S$. hystrix appeared equally susceptible to isolated predation and bleaching

$288\left(\chi^{2}=0.022, \mathrm{df}=1, \mathrm{p}=0.88\right)$.

Distribution surveys

We analyzed patterns of distribution using both entire $8 \times 8 \mathrm{~m}$ plots and after excluding habitat deemed unsuitable for P. damicornis or S. hystrix (e.g., sand-scoured channels and pools, bommie tops covered in rubble). The analyses using only suitable habitat were quantitatively similar to those using the entire plots but were more conservative. Neighborhood density graphs using only suitable habitat are included here. Neighborhood density analysis indicated that both P. damicornis and S. hystrix were significantly aggregated at up to $1 \mathrm{~m}$ when all size classes were considered and surveys from all villages were pooled (Fig. 4a \& b, respectively). When analyzed by site, the distance below which colonies were aggregated ranged from $<1 \mathrm{~m}$ in Votua and Vatu-o-lailai to nearly $3 \mathrm{~m}$ in Namada (see appendix). At no distance on any reef were colonies significantly overdispersed. 

that the largest colonies $(\geq 15 \mathrm{~cm})$ were not aggregated at any scale, but all smaller size classes were strongly aggregated at scales of up to $1 \mathrm{~m}$. Thus, smaller colonies appeared to drive the aggregation at up to $\sim 1 \mathrm{~m}$ when we analyzed all sizes together. However, the limited sample size for large colonies $(n=187)$ may have constrained our ability to detect spatial patterns for large colonies.

To resolve the spatial distribution of $P$. damicornis and $S$. hystrix more finely, we conducted separate circular surveys (radius $=2 \mathrm{~m}$ ) around focal colonies that met specific criteria. Across all $2 \mathrm{~m}$, there was a significant negative relationship between distance from focal P. damicornis colonies and radial $P$. damicornis count (corrected for area surveyed at each

311 distance and henceforth called density), focal P. damicornis and radial S. hystrix density, and

312 focal $S$. hystrix and radial $P$. damicornis density (GLM: $\mathrm{z}=-4.4, \mathrm{p}<0.0001 ; \mathrm{z}=-3.9, \mathrm{p}<0.0005$; $\mathrm{z}=-$ 3.6, $\mathrm{p}<0.0005$, respectively) (Fig. 5a \& b). The relationships within the first $0.5 \mathrm{~m}$ or $1 \mathrm{~m}$ for these focal-radial combinations were not significant (see Table 1 for all values not provided in 315 text).

Across all $2 \mathrm{~m}$, there was no significant relationship between distance from focal $S$. a significant positive relationship between distance and density within the first $0.5 \mathrm{~m}$ (GLM, z=$12.99, \mathrm{p}<0.05)$ but not within the first $1 \mathrm{~m}$.

When we converted the $8 \times 8 \mathrm{~m}$ surveys into data analogous to the circular surveys and considered any $P$. damicornis colony $\geq 15 \mathrm{~cm}$ across as a focal colony and any smaller individual as a radial colony, there was a significant negative relationship between distance and radial $P$.

323 damicornis density (GLM, $\mathrm{z}=-3.6, \mathrm{p}<0.0005)$ across all $2 \mathrm{~m}$ but not across the first $0.5 \mathrm{~m}$ or $1 \mathrm{~m}$ 
324 (Fig. 5c; Table 2). However, when the cutoff for focal colonies was $20 \mathrm{~cm}$, there was no

325 relationship between distance and $P$. damicornis colony count at $0.5 \mathrm{~m}, 1 \mathrm{~m}$, or $2 \mathrm{~m}$ (Fig. 5c;

326 Table 2).

327

328 Discussion

Using small portions of adult $P$. damicornis and $S$. hystrix colonies to represent $\sim 6$ month old juveniles, we tested for distance-dependent survivorship as a function of proximity to adult conspecifics. Survival experiments with $P$. damicornis and S. hystrix fragments did not show distance-dependent mortality around conspecific adults (Fig. 2a \& b). The lack of distancedependent mortality in this study is consistent with a meta-analysis of distance-dependent mortality studies of the seeds and seedlings of terrestrial plants (Hyatt et al. 2003), in which distance from parents did not affect overall survival. However, when separated by life stage, that meta-analysis found that seedling survival increased with distance from parents while seed survival was not affected, suggesting that the strength of distance-dependent mortality may be a function of age. Our experiment using small coral fragments to represent juveniles attempted to conduct a similar test with corals. Our procedures would not have detected distance-dependent mortality of larvae occurring just after settlement. We would have preferred to conduct a reciprocal transplant experiment of fragments from both corals at differing distances to both conspecific and heterospecific adults but we were unable to gain permission to use that many coral colonies. Thus, we could document spatial patterns of survivorship relative to conspecific adults but not relative to heterospecific adults. our short-term experiment could not detect. Observed spatial patterns represent the balance of 
347 multiple, potentially opposing processes, such as greater recruit density near brooding parents

348 (similar to terrestrial seed shadows) versus detrimental effects of adult-associated enemies or

349 intraspecific competition on aggregated, nearby recruits. Rather than overdispersion, we found

350 significant clumping within $1 \mathrm{~m}$ of conspecifics for both $P$. damicornis and S. hystrix (Fig. 4a \&

351 b). The $8 \times 8 \mathrm{~m}$ surveys and the $2 \mathrm{~m}$ radius surveys both supported this pattern; there was a

352 significant negative relationship between $P$. damicornis radial colony density and distance from

353 focal $P$. damicornis and a nearly significant negative relationship (with a much more limited

354 sample size) between S. hystrix radial colony density and distance from focal S. hystrix (Fig. 5a

$355 \&$ b). We also observed a significant negative relationship between $S$. hystrix density and

356 distance from P. damicornis and P. damicornis density and distance from S. hystrix (Fig. 5a \&

357 b), suggesting that the cause of declining density with distance need not be species-specific.

358 Since $P$. damicornis and $S$. hystrix are confamilial, it is possible that they aggregate because a

359 location that is physiologically beneficial for one might also be beneficial for the other. We did

360 detect one pattern consistent with the Janzen-Connell hypothesis: small colonies of $P$.

361 damicornis were aggregated at scales of up to $1 \mathrm{~m}$, while colonies $\geq 15 \mathrm{~cm}$ in diameter were not

362 aggregated at any scale (Fig. 4). This selective loss of small colonies near adults is consistent

363 with the Janzen-Connell hypothesis, but is also consistent with self thinning from intraspecific

364 competition without mortality due to enemies aggregated near adults (Zhu et al. 2013).

There are a few potential causes for the observed clumping of conspecifics that could

counteract Janzen-Connell effects (Carlon and Olson 1993). Aggregated settlement near

maternal adults may occur for $P$. damicornis and $S$. hystrix because brooded planulae can settle quickly after release (Richmond 1987; Isomura and Nishihira 2001; Underwood et al. 2007;

369 Torda et al. 2013), and even if planulae disperse meters or kilometers, they may still aggregate 
370

371

372

373

374

375

376

378

379

380

381

382

383

384

385

386

387

388

389

390

391

392

near conspecific adults (Babcock 1988; Tioho, Tokeshi, and Nojima 2001; Doropoulos et al. 2015). Moreover, pocilloporid recruitment is inherently spatially heterogeneous (Dunstan and Johnson 1998) and occurs in hotspots that may be partially determined by water flow, density of adult confamilials (Eagle 2006), and substrate suitability (Harriott 1983; Lee, Walford and Goh 2009). Thus, multiple ecologically important processes and interactions can generate aggregation of juveniles, and some of these could overwhelm Janzen-Connell effects and make them seem unimportant in the field (at least in the short term), even if they were occurring.

The only other direct test of the Janzen-Connell hypothesis in corals was conducted on planulae and recruits of broadcasting Orbicella (formerly Montastraea) faveolata in the Caribbean (Marhaver et al. 2013). In that study distance-dependent mortality appeared to be microbially mediated, with effects differing upstream and downstream of focal $O$. faveolata. The design of that study and ours differs in several ways.

First, Marhaver et al. (2013) used planulae and recruits a few days old in their distancedependent survival experiments, whereas we used fragments taken from mature colonies. There are potential differences between fragments from adult corals and recruits. For example, the physiology, skeletal structure, and microbiomes of fragments from adults may differ from those of recruits and similarly sized juveniles (Vandermeulen and Watabe 1973; Harriott 1983; Le Tissier 1988; Christiansen et al. 2009). The planulae of $P$. damicornis have higher lipid percentages in their tissue than do adult colonies (Figueiredo et al. 2012), which could affect palatability and microbial defense. Most recruit mortality in the study by Marhaver et al. (2013) appeared to be microbe-related as opposed to predator-generated. In contrast, predators generated considerable mortality of our juvenile sized transplants. Liberally assuming that every bleaching death in our study was due to microbes, only about one quarter of $P$. damicornis and 
393 half of S. hystrix fragments could have died directly because of microbes; thus, about 50-75\% of

394 the mortality we observed appeared to be due to consumption by fish. One way in which using

395 colony fragments may not have been so different from using recruits was that both age categories

396 may have similar zooxanthellae endosymbionts, since $P$. damicornis vertically transfers

397 zooxanthellae to its young (LaJeunesse et al. 2004).

398 Second, Marhaver et al. (2013) studied the broadcast spawning species O. faveolata,

399 while we studied two brooding species whose planulae may be more likely to settle near their

400 parents, and whose larvae may receive critical components of their microbiome via vertical

401 transmission from adults. Data on the make-up and function of juvenile coral microbiomes are

402 limited but at present there is some evidence that larvae from brooding species may be more

403 consistently endowed with parental components of the microbiome than are the larvae of

404 broadcast spawners (Littman, Willis, and Bourne 2009; Apprill et al. 2012; Sharp, Distel and

405 Paul 2012; Lema, Willis, and Bourne 2014). In some acroporid corals, juveniles do not develop

406 microbiomes typical of adult colonies until greater than 9 months of age (Littman, Willis, and

407 Bourne 2009) but a core component of the microbiome appears in all the early stages, despite

408 additions of other microbial species from the environment later in development (Lema, Willis,

409 and Bourne 2014). However, in brooding species such as Porites and Pocillopora, critical

410 microbes are transmitted from adults to larvae, or very quickly acquired from the environment,

411 and even very young juvenile stages resemble adults in their composition of key microbes

412 comprising the symbiotic microbiome (Apprill et al. 2012; Sharp, Distel, and Paul 2012). We do

413 not know these relationships for the species we investigated but if their microbiomes take months

414 to develop and are important defenses against microbial enemies, then our use of small adult

415 portions may not mimic juvenile susceptibility to adult-associated pathogens. In contrast, if the 
416 critical components of the microbiome are present in even the earliest stages, then our adult

417 fragments should be more representative. We would have preferred to use recently recruited

418 larvae but neither $P$. damicornis nor $S$. hystrix planulated at our study site during our experiment.

419 Finally, the focal adult colonies of Orbicella investigated by Marhaver et al. (2013) form

420 larger, longer-lived colonies than the colonies of Pocillopora and Seriatopora that we

421 investigated. It is possible that larger, longer-lived colonies accumulate more species-specific

422 enemies over their lifetimes; if so, this could more strongly suppress juvenile survivorship near

423 these longer-lived adults.

424 Although we did not detect distance-dependent mortality, we did document spatially

425 heterogeneous corallivory on $P$. damicornis. This may promote species coexistence by producing

426 a mosaic of favorable and unfavorable patches for $P$. damicornis across the reef (Levin and Paine

427 1974; Holt 1984). Corallivore activity can structure coral distribution on reefs in both the Pacific

428 and Caribbean (Neudecker 1979; Littler, Taylor, and Littler 1989) and parrotfish and

429 butterflyfish density can impact coral recruit and juvenile mortality, respectively (Penin et al.

430 2010). Localized predation by the triggerfish Balistapus undulatus on small P. damicornis could

431 have a similar effect here. Balistapus undulatus is a generalist with territories of $100-200 \mathrm{~m}^{2}$

432 (McClanahan 2000) and eats the tips of branching corals, including P. damicornis (Hiatt and

433 Strasburg 1960; Neudecker 1979). This triggerfish species' territoriality may delineate certain

434 patches on reefs in which some species (e.g., P. damicornis) have high mortality while other

435 species (e.g., S. hystrix) are not directly affected, akin to what is seen with seaweed in territories

436 of the steephead parrotfish on the Great Barrier Reef (Welsh and Bellwood 2012) or Pocillopora

437 and Pavona in the interaction between damselfish territories and roving corallivores in the

438 Eastern Pacific (Wellington 1982). Additional experiments are necessary to determine how 
439 patchy corallivory contributes to the coexistence of $P$. damicornis, $S$. hystrix, and corals in 440 general.

441 Overall we found little evidence for distance-dependent mortality relative to focal 442 conspecific adults and for the pattern of over-dispersion that distance-dependent mortality would 443 be expected to produce. Instead, both $P$. damicornis and $S$. hystrix aggregated at the scale of $1 \mathrm{~m}$ 444 or less, with a tendency for small colonies to be clumped around larger ones. These findings 445 suggest that local dispersal shadows or areas of physiological benefit near prospering adult 446 conspecifics equal or exceed Janzen-Connell effects for the brooding corals we studied on these 447 Fijian reef flats. Our experiments using small coral fragments did not detect distance-dependent 448 mortality by species-specific enemies; we did, however, observe spatially heterogeneous 449 corallivory on $P$. damicornis, which could facilitate species coexistence by delineating reef 450 patches that are more or less favorable to different corals.

\section{Acknowledgments}

We thank the Fijian government and the Korolevu-i-wai district environmental and two anonymous reviewers for helpful comments. 
457

458

459

460

461

462

463

464

465

466

467

468

469

470

471

472

473

474

475

476

477

478

479

480

481

482

483

484

485

486

487

488

489

490

491

492

493

494

495

496

497

498

499

500

501

502

\section{References}

Apprill A, Marlow HQ, Marntidale MQ, Rappe MS. 2012. Specificity of associates between bacteria and the coral Pocillopora meandrina during early development. Applied Environmental Microbiology 70: 7467-7475.

Babcock R. 1988. Fine-scale spatial and temporal patterns in coral settlement. Proceeding of the 6th International Coral Reef Symposium 2:635-639.

Bagchi R, Gallery RE, Gripenberg S, Gurr SJ, Narayan L, Addis CE, Freckleton RP, Lewis OT. 2014. Pathogens and insect herbivores drive rainforest plant diversity and composition. Nature 506:85-88.

Bates D, Maechler M, Bolker B, Walker S. 2013. lme4: Linear mixed-effects models using Eigen and S4. R package version 1.0-5. http://CRAN.R-project.org/package=lme4.

Ben-Haim Y, Zicherman-Keren M, Rosenberg E. 2003. Temperature-regulated bleaching and lysis of the coral Pocillopora damicornis by the novel pathogen Vibrio coralliilyticus. Applied Environmental Microbiology 69:4236-4242.

Bernays, EA. 1989. Host range in phytophagous insects: the potential role of generalist predators. Evolutionary Ecology 3:299-311.

Bonaldo RM, Hay ME. 2014. Seaweed-coral interactions: variance in seaweed allelopathy, coral susceptibility, and potential effects on coral resilience. PLoS One 9:e85786

Buss LW, Jackson JBC. 1979. Competitive networks: nontransitive competitive relationships in cryptic coral reef environments. American Naturalist 113:223-234.

Carlon DB, Olson RR. 1993. Larval dispersal distance as an explanation for adult spatial pattern in two Caribbean reef corals. Journal of Experimental Marine Biology and Ecology 173:247-263.

Christiansen N, Ward S, Harii S, Tibbetts I. 2009. Grazing by a small fish affects the early stages of a post-settlement stony coral. Coral Reefs 28:47-51.

Connell JH. 1971. On the role of natural enemies in preventing competitive exclusion in some marine animals and in rain forest trees. In: Den Boer PJ and Gradwell GR (eds): Dynamics of Population. Wageningen, Pudoc 298-312.

Connell JH. 1978. Diversity in tropical rain forests and coral reefs. Science 199:1302-1310

Cornell JH, Karlson R. 2000. Coral species richness: ecological versus biogeographical influences. Coral Reefs 19:37-49.

Doropoulos C, Ward S, Roff G, Gonzalez-Rivero M, Mumby PJ. 2015. Linking demographic processes of juvenile corals to benthic recovery trajectories in two common reef habitats. PLoS ONE 10(5): e0128535. doi:10.1371/journal.pone.0128535

Dixson DL, Abrego D, Hay ME. 2014. Chemically-mediated behavior of recruiting corals and fishes: a tipping point that may limit reef recovery. Science 345:892-897.

Dunstan P, Johnson C. 1998. Spatio-temporal variation in coral recruitment at different scales on Heron Reef, southern Great Barrier Reef. Coral Reefs 17:71-81.

Eagle JV. 2006. Recruitment hotspots around a coral reef: the roles of hydrodynamics and habitats. Ph.D theis, James Cook University

Fan TY, Li JJ, Ie SX, Fang LS. 2002. Lunar periodicity of larval release by pocilloporid corals in southern Taiwan. Zoological Studies 41:288-294.

Figueiredo J, Baird AH, Cohen MF, Flot J-F, Kamiki T, Meziane T, Tsuchiya M, Yamasaki H. 2012. Ontogenetic change in the lipid and fatty acid composition of scleractinian coral larvae. Coral Reefs 31:613-619. 
503

504

505

506

507

508

509

510

511

512

513

514

515

516

517

518

519

520

521

522

523

524

525

526

527

528

529

530

531

532

533

534

535

536

537

538

539

540

541

542

543

544

545

546

547

548

Fricke EC, Tewksbury JJ, Rogers HS. 2014. Multiple natural enemies cause density-dependent mortality at the seed-to-seeding transition. Ecology Letters 17: 593-598.

Harriott VJ. 1983. Reproductive seasonality, settlement, and post-settlement mortality of Pocillopora damicornis (Linnaeus), at Lizard Island, Great Barrier Reef. Coral Reefs 2:151-157.

Hiatt RW, Strasburg DW. 1960. Ecological relationships of the fish fauna on coral reefs of the Marshall Islands. Ecological Monographs 30:65-127.

Holt RD. 1984. Spatial heterogeneity, indirect interactions, and the coexistence of prey species. American Naturalist 124:377-406.

Hyatt LA, Rosenberg MS, Howard TG, Bole G, Fang W, Anastasia J, Brown K, Grella R, Hinman K, Kurdziel JP. 2003. The distance dependence prediction of the Janzen-Connell hypothesis: a meta-analysis. Oikos 103:590-602.

Isomura N, Nishihira M. 2001. Size variation of planulae and its effect on the lifetime of planulae in three pocilloporid corals. Coral Reefs 20:309-315.

Jayewardene D, Donahue MJ, Birkeland C. 2009. Effects of frequent fish predation on corals in Hawaii. Coral Reefs 28:499-506.

Janzen DH. 1970. Herbivores and the number of tree species in tropical forests. American Naturalist 104:501-528.

Johnson DJ, Beaulieu WT, Bever JD, Clay K. 2012. Conspecific negative density dependence and forest diversity. Science 336:904-907.

Jones G, Almany G, Russ G, Sale P, Steneck R, Van Oppen M, Willis B. 2009. Larval retention and connectivity among populations of corals and reef fishes: history, advances and challenges. Coral Reefs 28:307-325.

Kuanui P, Chavanich S, Raksasab C, Viyakarn V. 2008. Lunar periodicity of larval release and larval development of Pocillopora damicornis in Thailand. Mar Freshw Res 11:375-377.

LaJeunesse TC, Thornhall DJ, Cox EF, Stanton FG, Fitt WK, Schmidt GW. 2004. High diversity and host specificity observed among symbiotic dinoflagellates in reef coral communities from Hawaii. Coral Reefs 23:596-603.

Lang J. 1973. Interspecific aggression by scleractinian corals. 2 . Why the race is not only to the swift. Bulletin of Marine Science 23:260-279.

Le Tissier M D'A A. 1988. Patterns of formation and the ultrastructure of the larval skeleton of Pocillopora damicornis. Marine Biology 98:493-501.

Lee CS, Walford J, Goh BPL. 2009. Adding coral rubble to substrata enhances settlement of Pocillopora damicornis larvae. Coral Reefs 28:529-533.

Lema KA, Willis BL, Bourne DG. 2012. Corals form characteristic associations with symbiotic nitrogen-fixing bacteria. Applied Environmental Microbiology 78:3136-3144.

Lenihan HS, Holbrook SJ, Schmitt RJ, Brooks AJ. 2011. Influence of corallivory, competition, and habitat structure on coral community shift. Ecology 92:1959-1971.

Levin SA, Paine RT. 1974. Disturbance, patch formation, and community structure. Proceeding of the National Academy of Sciences 71:2744-2747.

Littler MM, Taylor PR, Littler DS. 1989. Complex interactions in the control of coral zonation on a Caribbean reef flat. Oecologia 80:331-340.

Littman RA, Willis BL, Bourne DG. 2009. Bacterial communities of juvenile corals infected with different Symbiodinium (dinoflagellate) clades. Marine Ecology Progress Series 389:45-59.

Marhaver K, Vermeij M, Rohwer F, Sandin S. 2013. Janzen-Connell effects in a broadcast- 
spawning Caribbean coral: distance-dependent survival of larvae and settlers. Ecology 94:146-160.

McClanahan T. 2000. Recovery of a coral reef keystone predator, Balistapus undulatus, in East African marine parks. Biological Conservation 94:191-198.

Miller K, Mundy C. 2003. Rapid settlement in broadcast spawning corals: implications for larval dispersal. Coral Reefs 22:99-106.

Nathan N, Casagrandi R. 2004. A simple mechanistic model of seed dispersal, predation and plant establishment: Janzen-Connell and beyond. Journal of Ecology 92: 733-746.

Neudecker S. 1979. Effects of grazing and browsing fishes on the zonation of corals in Guam. Ecology 60:666-672.

Nozawa Y, Harrison PL. 2008. Temporal patterns of larval settlement and survivorship of two broadcast-spawning acroporid corals. Marine Biology 155:347-351.

Packer A, Clay K. 2000. Soil pathogens and spatial patterns of seedling mortality in a temperate tree. Nature 404:278-281.

Penin L, Michonneau F, Baird AH, Connolly SR, Pratchett MS, Kayal M, Adjeroud M. 2010. Early post-settlement mortality and the structure of coral assemblages. Marine Ecology Progress Series 408:55-64.

Petermann JS, Fergus AJ, Turnbull LA, Schmid B. 2008. Janzen-Connell effects are widespread and strong enough to maintain diversity in grasslands. Ecology 89:2399-2406.

Porter JW, Woodley JD, Jason Smith G, Neigel JE, Battey JF, Dallmeyer DG. 1981. Population trends among Jamaican reef corals. Nature 294:249-250.

Pratchett MS. 2007. Dietary selection by coral-feeding butterflyfishes (Chaetodontidae) on the Great Barrier Reef, Australia. Rafflesia Bulletin of Zoology 14:155-160.

Price N. 2010. Habitat selection, facilitation, and biotic settlement cues affect distribution and performance of coral recruits in French Polynesia. Oecologia 163:747-758.

R Core Team. 2014). R: A language and environment for statistical computing. R Foundation for Statistical Computing, Vienna, Austria. URL http:/www.R-project.org/

Rasband WS. 1997. ImageJ, US National Institutes of Health, Bethesda, Maryland, USA

Rasher DB, Hoey AS, Hay ME. 2013. Consumer diversity interacts with prey defenses to drive ecosystem function. Ecology 94:1347-1358.

Richmond R. 1987. Energetics, competency, and long-distance dispersal of planula larvae of the coral Pocillopora damicornis. Marine Biology 93:527-533.

Roff G, Mumby PJ. 2012. Global disparity in the resilience of coral reefs. Trends in Ecology and Evolution 27:404-413.

Rotjan RD, Lewis SM. 2008. Impact of coral predators on tropical reefs. Marine Ecology Progress Series 367:73-91.

Sato M. 1985. Mortality and growth of juvenile coral Pocillopora damicornis (Linnaeus). Coral Reefs 4:27-33.

Sharp KH, Distel D, Paul VJ. 2012. Diversity and dynamics of bacterial communities in early life stages of the Caribbean coral Porites astreoides. ISME Journal 6:790-801.

Smith JE, Shaw M, Edwards RA, Obura D, Pantos O, Sala E, Sandin SA, Smriga S, Hatay M, Rohwer FL. 2006. Indirect effects of algae on coral: algae-mediated, microbe-induced coral mortality. Ecology Letters 9:835-845.

Therneau T. 2012). coxme: Mixed Effects Cox Models.. R package version 2.2-3. http://CRAN.R-project.org/package=coxme

Tioho H, Tokeshi M, Nojima S. 2001. Experimental analysis of recruitment in a scleractinian 
595

596

597

598

599

600

601

602

603

604

605

606

607

608

609

610

611

612

613

614

615

616

coral at high latitude. Marine Ecology Progress Series 213:79-86.

Torda G, Lundgren P, Willis B, Oppen M. 2013. Revisiting the connectivity puzzle of the common coral Pocillopora damicornis. Molecular Ecology 22:5805-5820.

Underwood J, Smith L, Van Oppen M, Gilmour J. 2007. Multiple scales of genetic connectivity in a brooding coral on isolated reefs following catastrophic bleaching. Molecular Ecology 16:771-784.

Vandermeulen JH, Watabe N. 1973. Studies on reef corals. I. Skeleton formation by newly settled planula larva of Pocillopora damicornis. Marine Biology 23: 47-57.

Vermeij MJ. 2005. Substrate composition and adult distribution determine recruitment patterns in a Caribbean brooding coral. Marine Ecology Progress Series 295:123-133.

Vermeij MJ, Sandin SA. 2008. Density-dependent settlement and mortality structure the earliest life phases of a coral population. Ecology 89:1994-2004.

Wellington GM. 1982. Depth zonation of corals in the Gulf of Panama: control and facilitation by resident reef fishes. Ecological Monographs 52:223-241.

Welsh J, Bellwood D. 2012. Spatial ecology of the steephead parrotfish (Chlorurus microrhinos): an evaluation using acoustic telemetry. Coral Reefs 31:55-65.

Wiegand T, Moloney AK. 2004. Rings, circles, and null-models for point pattern analysis in ecology. Oikos 104:209-229.

Zhu Y, Getzin S, Wiegand T, Ren H, Ma K. 2013. The relative importance of Janzen-Connell effects in influencing the spatial patterns at the Gutianshan subtropical forest. PLoS One $8: \mathrm{e} 74560$ 


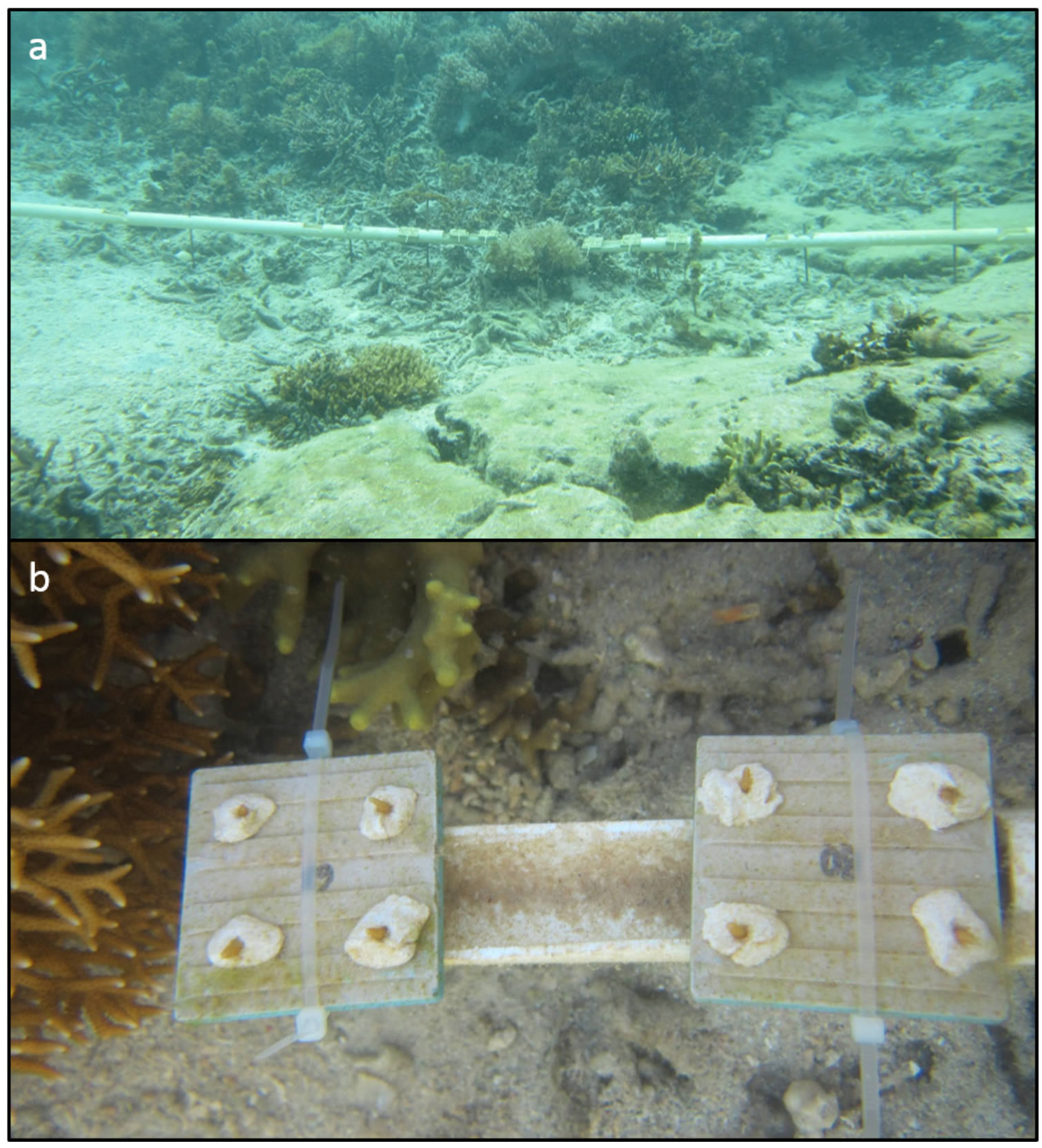

619 Figure 1- Experimental set up of coral fragments epoxied to tiles on PVC pipes around focal adult colonies. a) PVC pipes radiating outwards from a focal Seriatopora hystrix colony. b) Fragments epoxied onto ceramic tiles around an S. hystrix colony. 

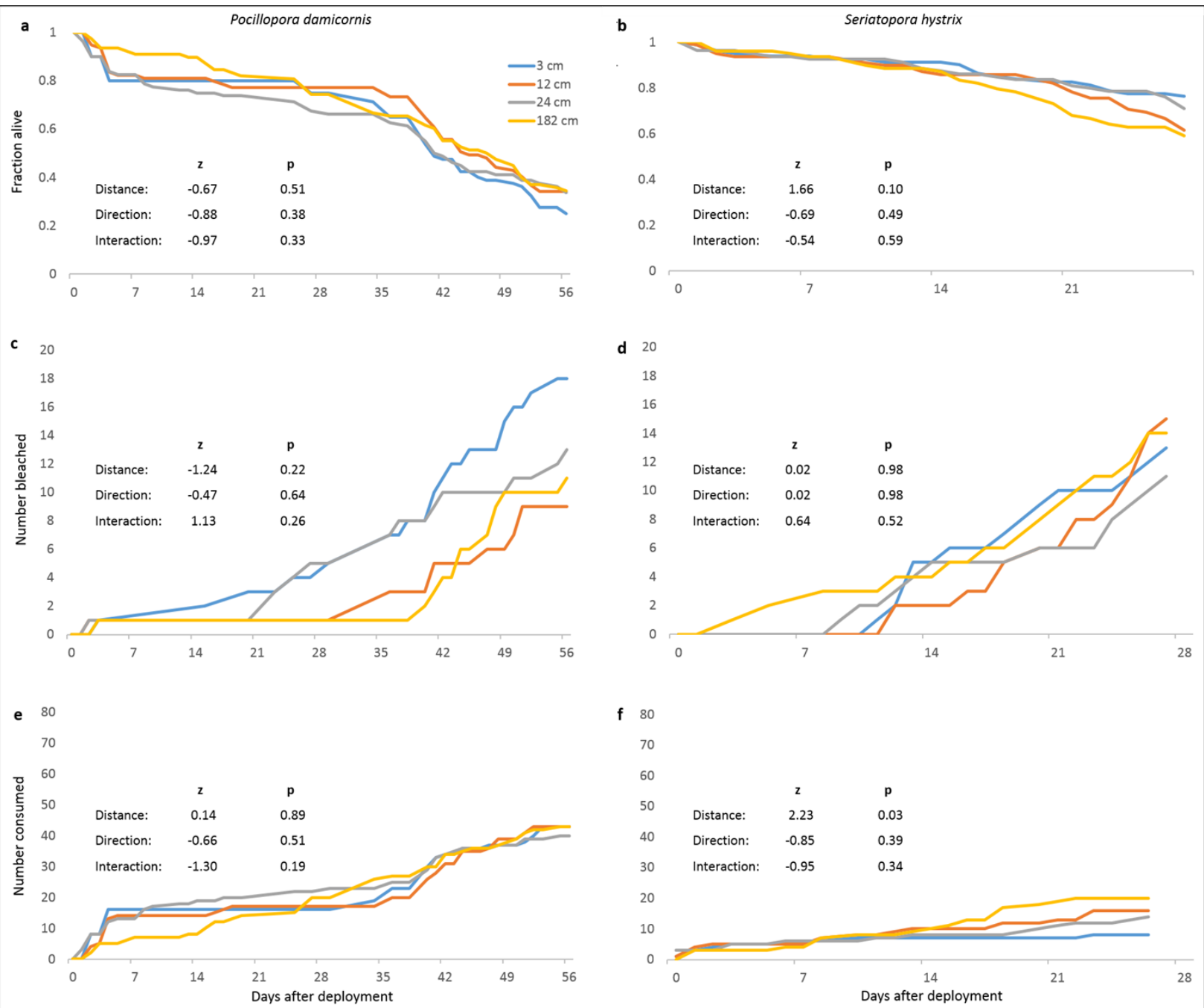

Figure 2- Left column is Pocillopora damicornis and right column is Seriatopora hystrix. $\mathrm{n}=80$ fragments at each distance across 10 focal colonies and pooled between both hystrix fragments. c \& d) Cumulative number of fragments that bleached over time. e \& f) Cumulative number of fragments that partially or fully disappeared over time (putative predation). 


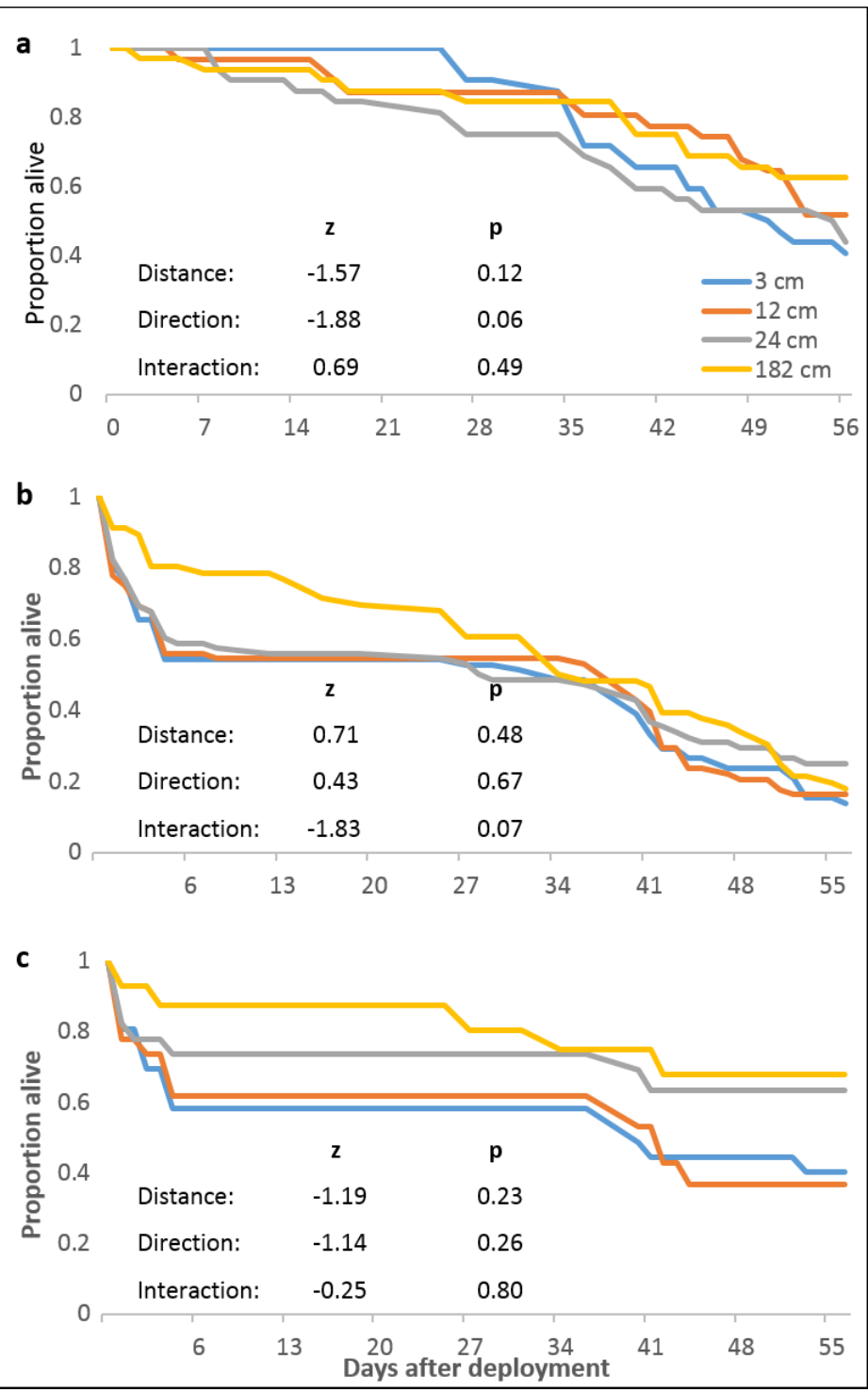

631 Figure 3- a) Survival of Pocillopora damicornis fragments in replicates (4 focal colonies, 32 fragments at each distance) that did not experience localized predation. b) Survival of $P$. damicornis fragments in the six focal colony replicates that did experience localized predation and in the replacement replicates. Deaths are from all causes. c) Fraction of $P$. damicornis fragments not killed by localized predation episodes in original replicates that experienced localized predation and in the replacement replicates. Direction not shown. Analyses as in Fig. 2. 
a $3 \quad P$. damicornis, colonies of all sizes

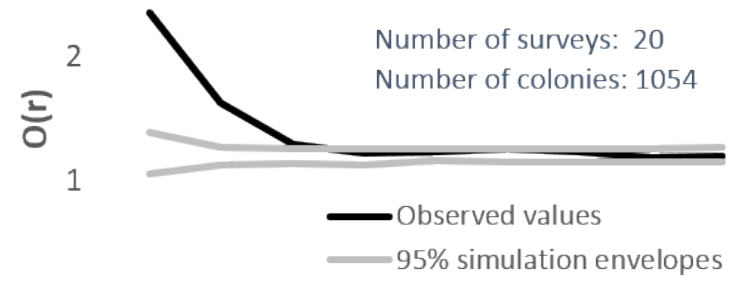

0

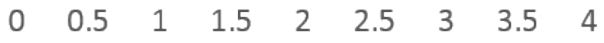

c $6 \quad$ P. damicornis, colonies $<5 \mathrm{~cm}$ diameter

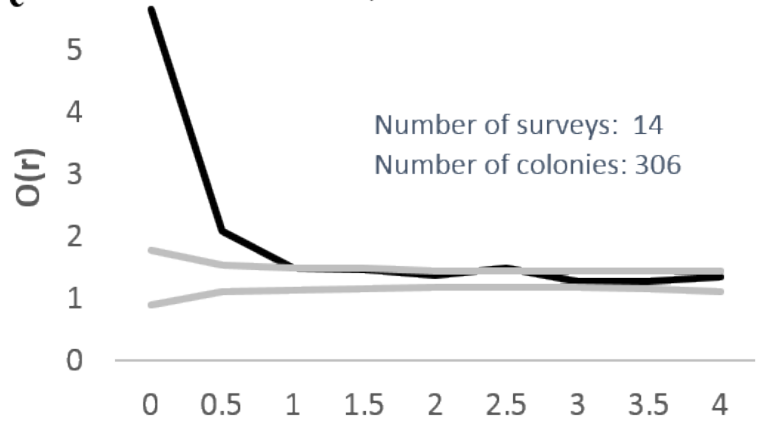

e $2.5 P$. damicornis, colonies $\geq 10 \mathrm{~cm}$ diameter

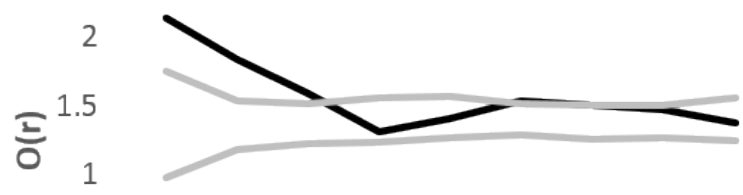

0.5

0

Number of surveys: 14

Number of colonies: 355

$\begin{array}{lllllllll}0 & 0.5 & 1 & 1.5 & 2 & 2.5 & 3 & 3.5 & 4\end{array}$ b 3

S. hystrix, colonies of all sizes

2.5

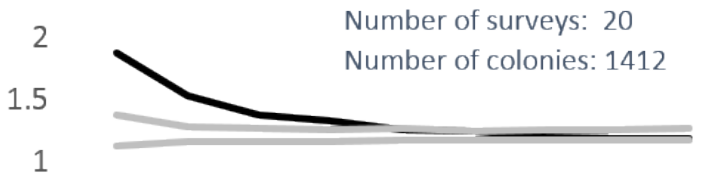

0.5

0

$\begin{array}{lllllllll}0 & 0.5 & 1 & 1.5 & 2 & 2.5 & 3 & 3.5 & 4\end{array}$

d $2.5 \quad$ P. damicornis, colonies $\geq 5 \mathrm{~cm}$ diameter

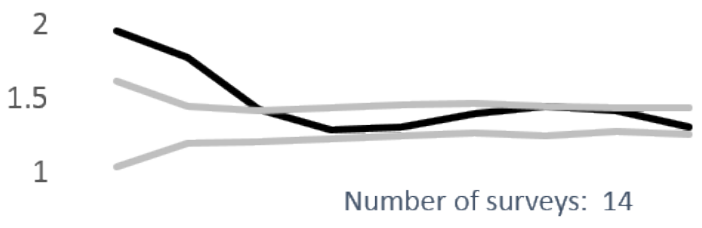

0.5

Number of colonies: 485

0

$\begin{array}{lllllllll}0 & 0.5 & 1 & 1.5 & 2 & 2.5 & 3 & 3.5 & 4\end{array}$

f $2.5 \quad P$. damicornis, colonies $\geq 15 \mathrm{~cm}$ diameter

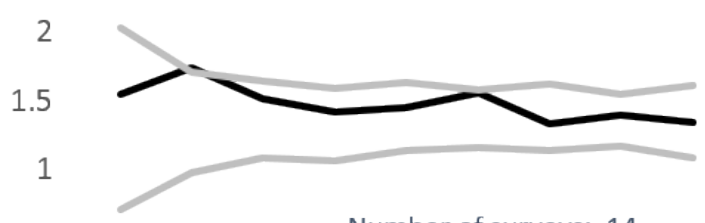

0.5

Number of surveys: 14

Number of colonies: 187

$\begin{array}{lllllllll}0 & 0.5 & 1 & 1.5 & 2 & 2.5 & 3 & 3.5 & 4\end{array}$
639

640

641

642

643

644

645

646

647

Figure 4- Neighborhood density analysis of Pocillopora damicornis and Seriatopora hystrix in 8

x 8 m quadrats with replicates from all three reefs combined. Black lines are observed patterns; grey lines are the 95\% simulation envelopes from 999 simulations. Where black lines are above the upper grey line colonies are significantly aggregated, where they are between the grey lines colonies are randomly spaced, and where they are below the lower grey line colonies are significantly overdispersed. These analyses used only areas of suitable substrate (see text for definition). 


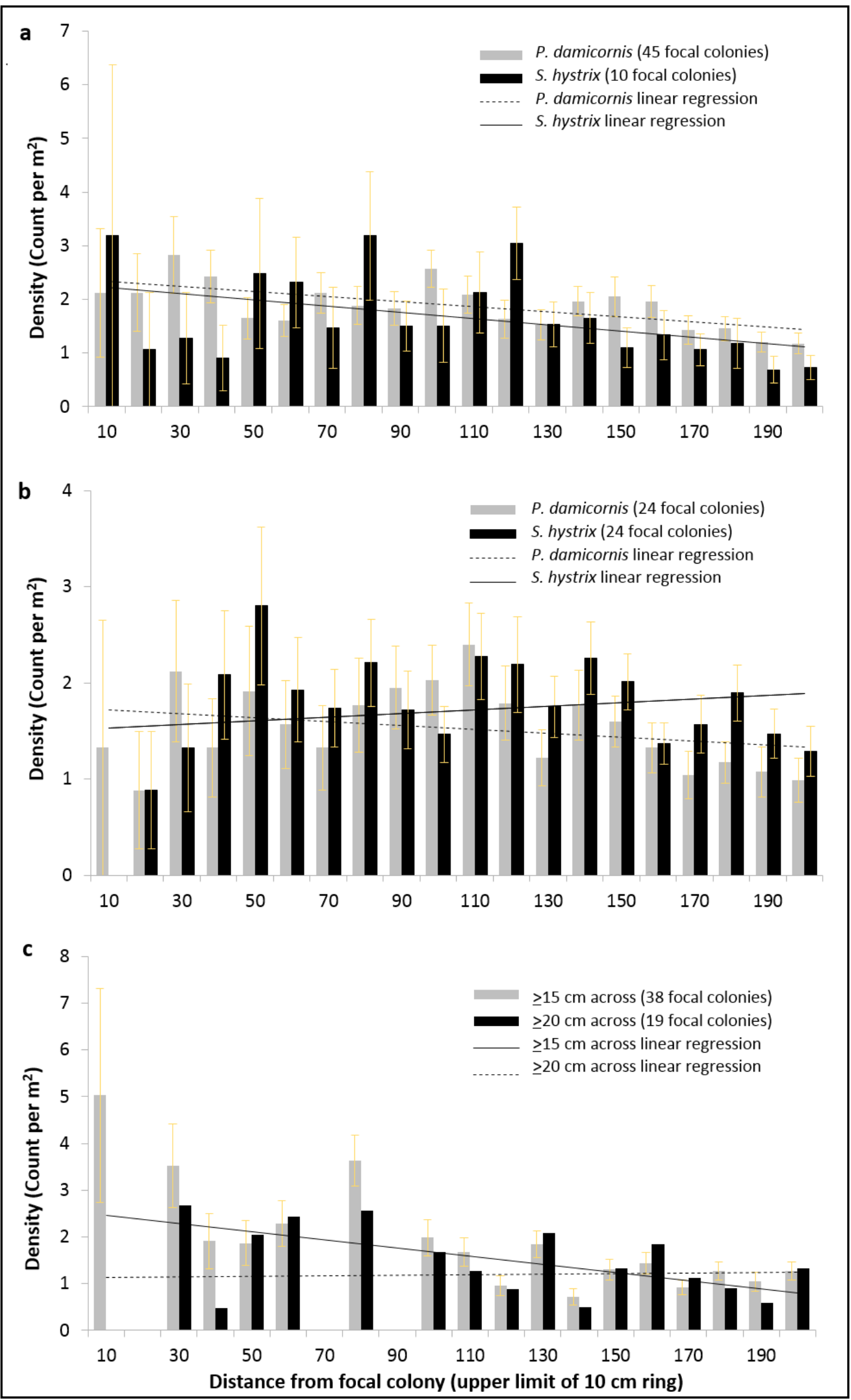


649 Figure 5- Density ( \pm SE) of Pocillopora damicornis and Seriatopora hystrix at $10 \mathrm{~cm}$ intervals 650 from focal a) P. damicornis and b) S. hystrix colonies. The linear regressions shown are 651 to indicate the slope of the relationship found in the generalized linear mixed effects models but do not represent the models' outputs. Radial colony count significantly declined with distance from focal colony over $2 \mathrm{~m}$ for three of the four focal-radial combinations (focal P. damicornis-radial P. damicornis- $-\mathrm{z}=-4.4, \mathrm{p}<0.001$; focal $P$. damicornis-radial S. hystrix - z=-3.9, $\mathrm{p}<0.001$; focal S. hystrix-radial P. damicornis$\mathrm{z}=-3.6, \mathrm{p}<0.001$; focal $S$. hystrix-radial $S$. hystrix $-\mathrm{z}=-1.9, \mathrm{p}=0.06) . \mathrm{c})$ Density (mean \pm SE) of Pocillopora damicornis within $2 \mathrm{~m}$ of focal P. damicornis based on the $8 \times 8 \mathrm{~m}$ surveys. Focal colonies are $P$. damicornis that are $\geq 15 \mathrm{~cm}$ across or $\geq 20 \mathrm{~cm}$ across. Radial colonies are any colonies below that size. Radial colony count significantly declined with distance over $2 \mathrm{~m}$ when colonies $\geq 15 \mathrm{~cm}$ were considered focal (focal colonies $\geq 15 \mathrm{~cm}-\mathrm{z}=-3.6, \mathrm{p}<0.0005$; focal colonies $\geq 20 \mathrm{~cm}-\mathrm{z}=-1.09, \mathrm{p}<0.27)$.

662

663 


\begin{tabular}{|c|c|c|c|c|}
\hline $\begin{array}{c}\text { Focal species- } \\
\text { radial species }\end{array}$ & $\begin{array}{c}\text { Maximum } \\
\text { distance }\end{array}$ & Slope & z value & p-value \\
\hline \hline \multirow{2}{*}{$\begin{array}{c}\text { P. damicornis- } \\
\text { P. damicornis }\end{array}$} & $0.50 \mathrm{~m}$ & -0.0098 & -1.0 & 0.32 \\
\cline { 2 - 5 } & $1.0 \mathrm{~m}$ & 0.00055 & 0.22 & 0.83 \\
\hline \multirow{3}{*}{$\begin{array}{c}\text { P. damicornis- } \\
\text { S. hystrix }\end{array}$} & $0.0 \mathrm{~m}$ & -0.0032 & -4.4 & $<0.0001$ \\
\cline { 2 - 5 } & $1.0 \mathrm{~m}$ & 0.016 & 0.59 & 0.56 \\
\cline { 2 - 5 } & $2.0 \mathrm{~m}$ & -0.0012 & 0.19 & 0.85 \\
\hline \multirow{3}{*}{$\begin{array}{c}\text { S. hystrix- } \\
\text { P. damicornis }\end{array}$} & $0.50 \mathrm{~m}$ & 0.0099 & -3.9 & $<0.0005$ \\
\cline { 2 - 5 } & $1.0 \mathrm{~m}$ & 0.0042 & 1.1 & 0.57 \\
\hline \multirow{2}{*}{$\begin{array}{c}\text { S. hystrix- } \\
\text { S. hystrix }\end{array}$} & $2.0 \mathrm{~m}$ & -0.0036 & -3.6 & $<0.0005$ \\
\cline { 2 - 5 } & $1.0 \mathrm{~m}$ & 0.042 & 2.3 & $<0.05$ \\
\cline { 2 - 5 } & $2.0 \mathrm{~m}$ & -0.00065 & -0.18 & 0.86 \\
\hline
\end{tabular}

Table 1- Relationship between count of radial Pocillopora damicornis and Seriatopora hystrix colonies and distance from focal P. damicornis and S. hystrix colonies using generalized linear mixed effects models. "Maximum distance" is the distance up to which radial colonies were considered.

665

666

667

668 


\begin{tabular}{|c|c|c|c|c|}
\hline $\begin{array}{c}\text { Threshold size } \\
\text { for focal colony }\end{array}$ & $\begin{array}{c}\text { Maximum } \\
\text { distance }\end{array}$ & Slope & $z$ value & p-value \\
\hline \hline \multirow{3}{*}{$15 \mathrm{~cm}$} & $0.50 \mathrm{~m}$ & -0.0064 & -0.46 & 0.65 \\
\cline { 2 - 5 } & $1.0 \mathrm{~m}$ & -0.0063 & -1.5 & 0.14 \\
\cline { 2 - 5 } & $2.0 \mathrm{~m}$ & -0.0034 & -3.6 & $<0.0005$ \\
\hline \multirow{3}{*}{$20 \mathrm{~cm}$} & $0.50 \mathrm{~m}$ & 0.047 & 1.2 & 0.23 \\
\cline { 2 - 5 } & $1.0 \mathrm{~m}$ & 0.00032 & 0.045 & 0.96 \\
\cline { 2 - 5 } & $2.0 \mathrm{~m}$ & -0.0016 & -1.09 & 0.27 \\
\hline
\end{tabular}

Table 2- Relationship between count of radial Pocillopora damicornis colonies and distance from focal Pocillopora damicornis colonies using the data from 671 the $8 \times 8 \mathrm{~m}$ surveys. "Threshold size for focal colony" is the size above which

surveyed colonies were designated

"focal" and below which colonies were designated "radial." "Maximum distance" is the distance up to which radial colonies were considered. 
1

Seriatopora hystrix fragments on tiles on PVC array

Figure 1- Experimental set up of coral fragments epoxied to tiles on PVC pipes around focal adult colonies. a) PVC pipes radiating outwards from a focal Seriatopora hystrix colony. b) Fragments epoxied onto ceramic tiles around an S. hystrix colony. 


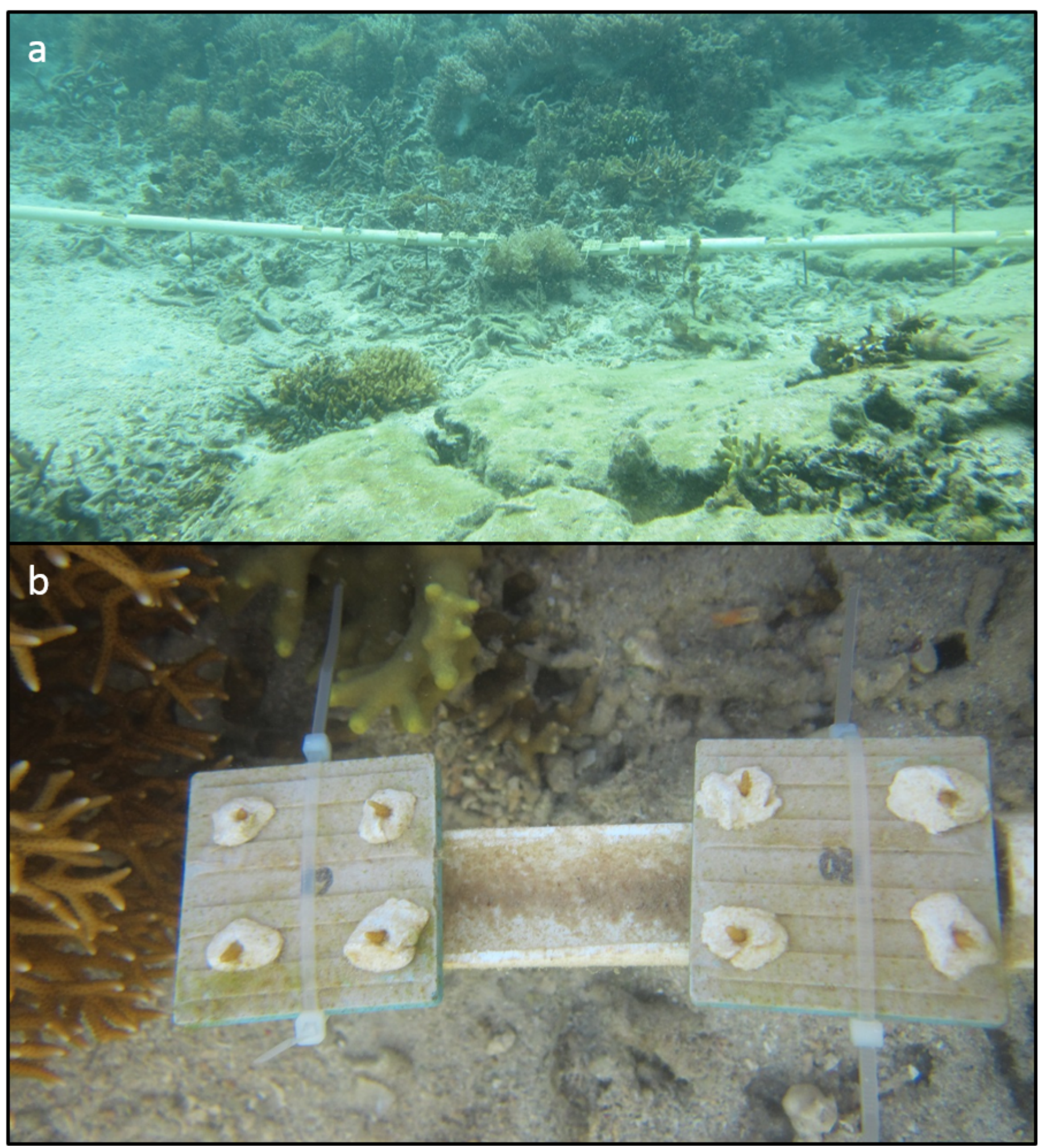


2

Survival and predation of Pocillopora damicornis and Seriatopora hystrix

Figure 2- Left column is Pocillopora damicornis and right column is Seriatopora hystrix.

Statistical values are from mixed-effects Cox proportional hazards survival analyses. $n=80$ fragments at each distance across 10 focal colonies and pooled between both directions. a \& b) Survivorship through time for Pocillopora damicornis and Seriatopora hystrix fragments. c $\&$ d) Cumulative number of fragments that bleached over time. $e \&$ f) Cumulative number of fragments that partially or fully disappeared over time (putative predation).

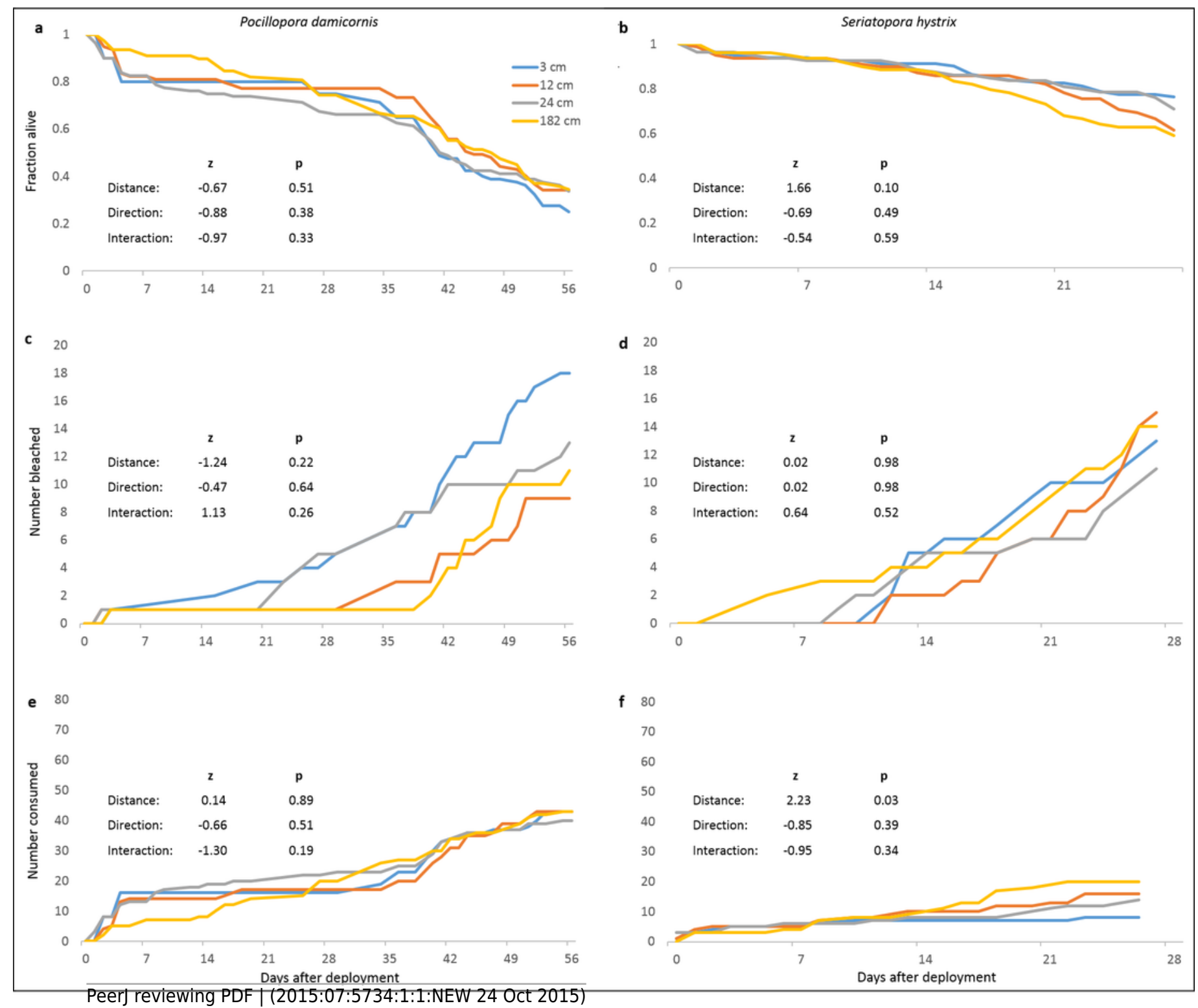


3

Pocillopora damicornis mortality relating to localized predation episodes

Figure 3- a) Survival of Pocillopora damicornis fragments in replicates (4 focal colonies, 32 fragments at each distance) that did not experience localized predation. b) Survival of $P$. damicornis fragments in the six focal colony replicates that did experience localized predation and in the replacement replicates. Deaths are from all causes. c) Fraction of $P$. damicornis fragments not killed by localized predation episodes in original replicates that experienced localized predation and in the replacement replicates. Direction not shown. Analyses as in Fig. 2. 


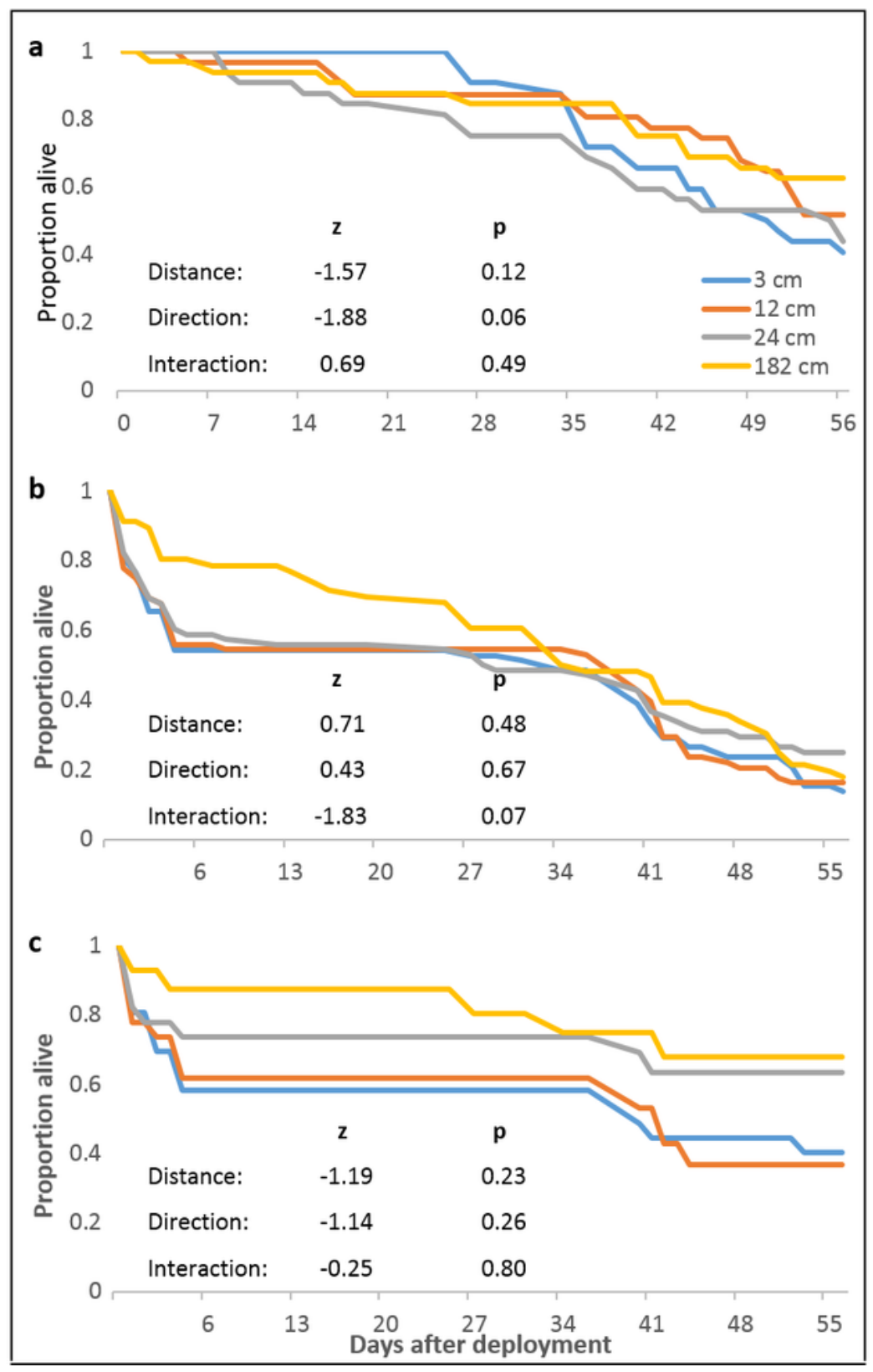




\section{4}

Neighborhood density analysis for Pocillopora damicornis and Seriatopora hystrix

Figure 4- Neighborhood density analysis of Pocillopora damicornis and Seriatopora hystrix in $8 \times 8 \mathrm{~m}$ quadrats with replicates from all three reefs combined. Black lines are observed patterns; grey lines are the $95 \%$ simulation envelopes from 999 simulations. Where black lines are above the upper grey line colonies are significantly aggregated, where they are between the grey lines colonies are randomly spaced, and where they are below the lower grey line colonies are significantly overdispersed. These analyses used only areas of suitable substrate (see text for definition). 


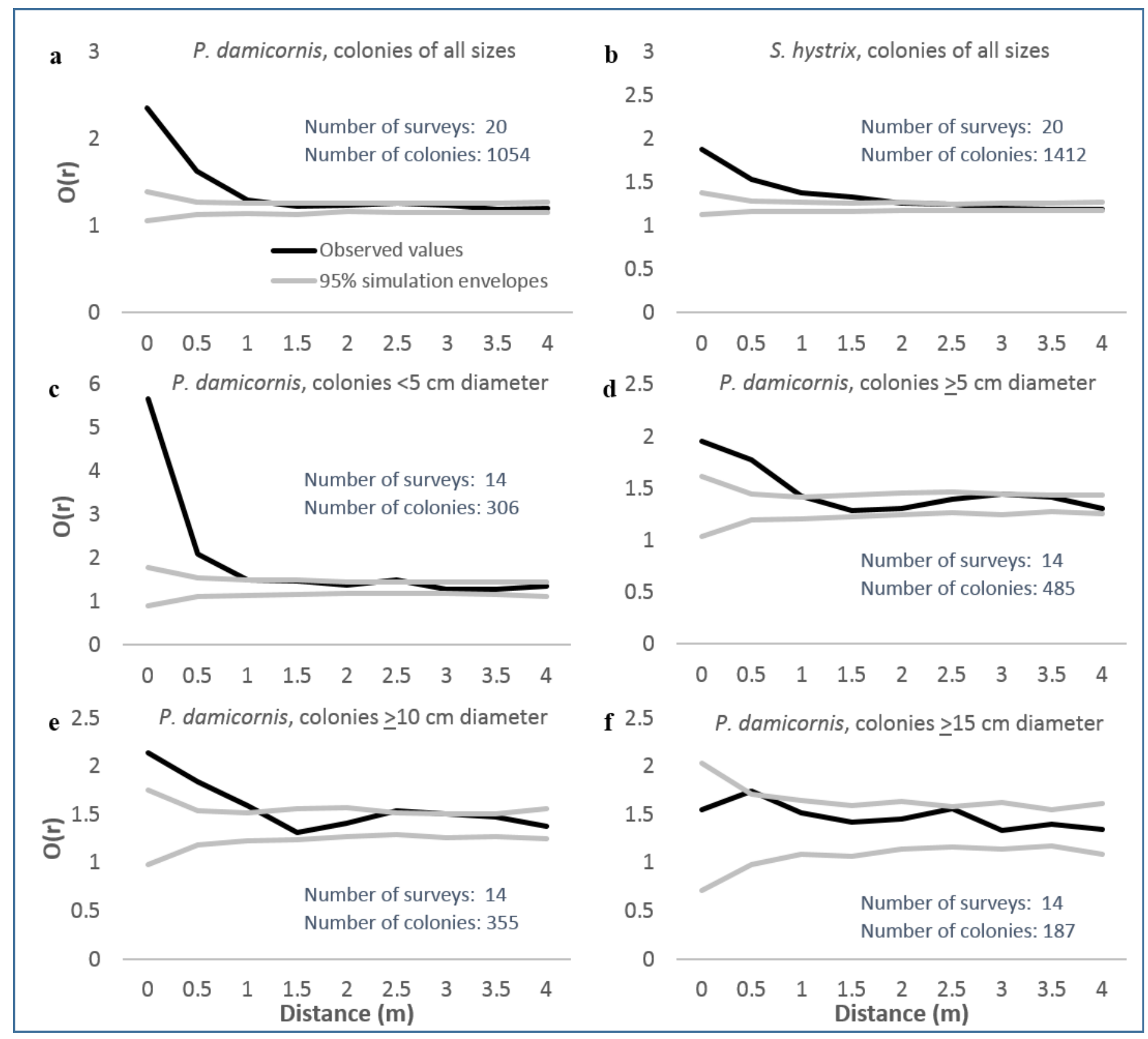




\section{5}

Density of Pocillopora damicornis and Seriatopora hystrix at $10 \mathrm{~cm}$ intervals around focal colonies

Figure 5- Density (+/- SE) of Pocillopora damicornis and Seriatopora hystrix at $10 \mathrm{~cm}$ intervals from focal a) $P$. damicornis and b) $S$. hystrix colonies. The linear regressions shown are to indicate the slope of the relationship found in the generalized linear mixed effects models but do not represent the models' outputs. Radial colony count significantly declined with distance from focal colony over $2 \mathrm{~m}$ for three of the four focal-radial combinations (focal P. damicornis-radial $P$. damicornis $-z=-4.4, p<0.001$; focal $P$. damicornis-radial S. hystrix$\mathrm{z}=-3.9, \mathrm{p}<0.001$; focal $S$. hystrix-radial $P$. damicornis $-\mathrm{z}=-3.6, \mathrm{p}<0.001$; focal $S$. hystrixradial S. hystrix $-\mathrm{z}=-1.9, \mathrm{p}=0.06$ ). c) Density (mean $+/$ - SE) of Pocillopora damicornis within $2 \mathrm{~m}$ of focal $P$. damicornis based on the $8 \times 8 \mathrm{~m}$ surveys. Focal colonies are $P$. damicornis that are $>=15 \mathrm{~cm}$ across or $>=20 \mathrm{~cm}$ across. Radial colonies are any colonies below that size. Radial colony count significantly declined with distance over $2 \mathrm{~m}$ when colonies $>=15$ $\mathrm{cm}$ were considered focal (focal colonies $>=15 \mathrm{~cm}-\mathrm{z}=-3.6, p<0.0005$; focal colonies $>=20$ $\mathrm{cm}-\mathrm{z}=-1.09, \mathrm{p}<0.27)$. 

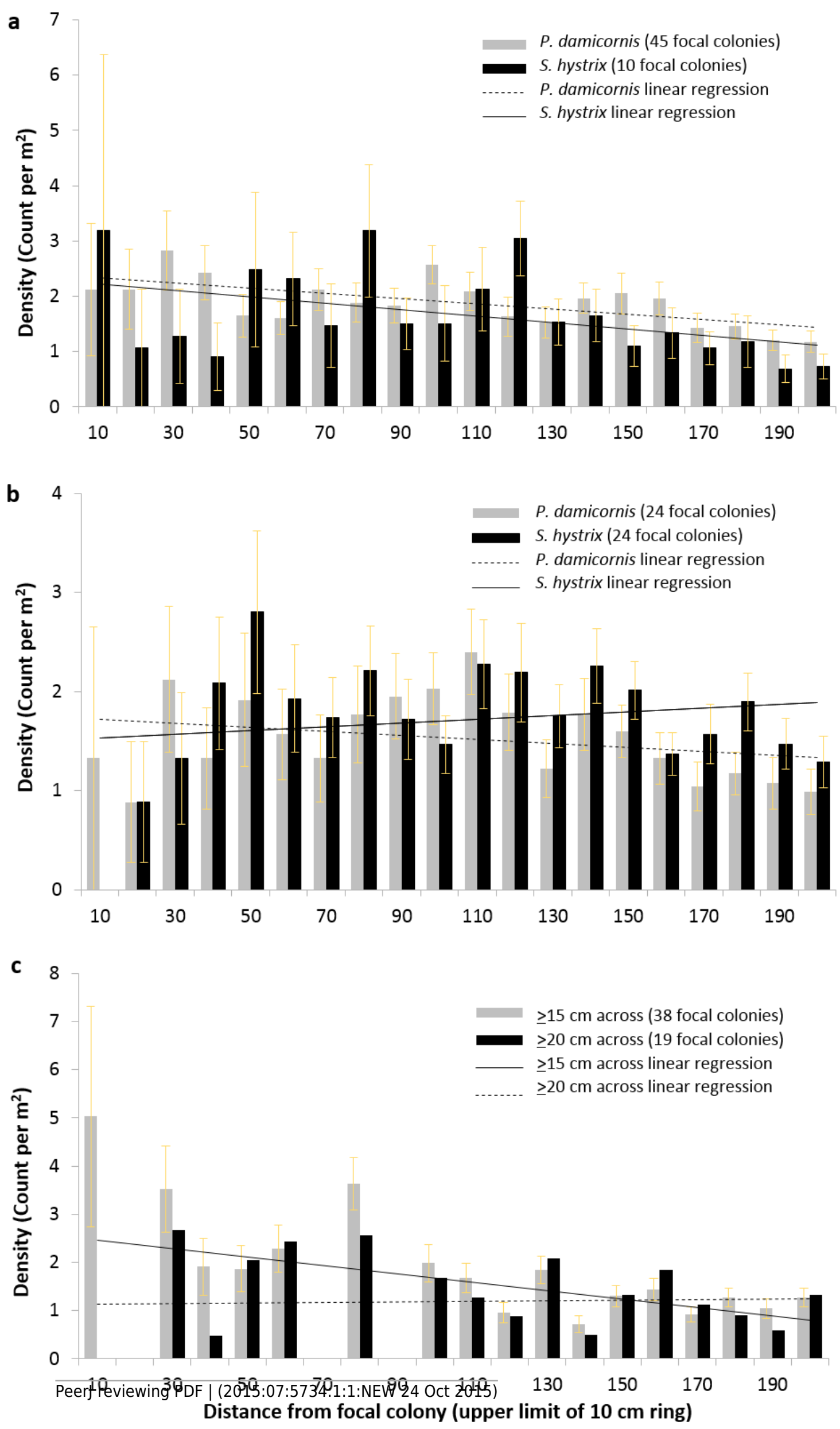


\section{Table $\mathbf{1}$ (on next page)}

Relationship between radial colony count and distance from focal colony

Table 1- Relationship between count of radial Pocillopora damicornis and Seriatopora hystrix colonies and distance from focal P. damicornis and S. hystrix colonies using generalized linear mixed effects models. "Maximum distance" is the distance up to which radial colonies were considered. 


\begin{tabular}{|c|c|c|c|c|}
\hline $\begin{array}{l}\text { Focal species- } \\
\text { radial species }\end{array}$ & $\begin{array}{c}\text { Maximum } \\
\text { distance }\end{array}$ & Slope & $z$ value & p-value \\
\hline \multirow{3}{*}{$\begin{array}{l}\text { P. damicornis- } \\
\text { P. damicornis }\end{array}$} & $0.50 \mathrm{~m}$ & -0.0098 & -1.0 & 0.32 \\
\hline & $1.0 \mathrm{~m}$ & 0.00055 & 0.22 & 0.83 \\
\hline & $2.0 \mathrm{~m}$ & -0.0032 & -4.4 & $<0.0001$ \\
\hline \multirow{3}{*}{$\begin{array}{l}\text { P. damicornis- } \\
\text { S. hystrix }\end{array}$} & $0.50 \mathrm{~m}$ & 0.016 & 0.59 & 0.56 \\
\hline & $1.0 \mathrm{~m}$ & 0.0012 & 0.19 & 0.85 \\
\hline & $2.0 \mathrm{~m}$ & -0.0057 & -3.9 & $<0.0005$ \\
\hline \multirow{3}{*}{$\begin{array}{c}\text { S. hystrix- } \\
\text { P. damicornis }\end{array}$} & $0.50 \mathrm{~m}$ & 0.0099 & 0.57 & 0.57 \\
\hline & $1.0 \mathrm{~m}$ & 0.0042 & 1.1 & 0.28 \\
\hline & $2.0 \mathrm{~m}$ & -0.0036 & -3.6 & $<0.0005$ \\
\hline \multirow{3}{*}{$\begin{array}{l}\text { S. hystrix- } \\
\text { S. hystrix }\end{array}$} & $0.50 \mathrm{~m}$ & 0.042 & 2.3 & $<0.05$ \\
\hline & $1.0 \mathrm{~m}$ & -0.00065 & -0.18 & 0.86 \\
\hline & $2.0 \mathrm{~m}$ & -0.0017 & -1.9 & 0.06 \\
\hline
\end{tabular}

1 


\section{Table 2 (on next page)}

$8 \times 8$ survey results converted to radial survey results

Table 2- Relationship between count of radial Pocillopora damicornis colonies and distance from focal Pocillopora damicornis colonies using the data from the $8 \times 8 \mathrm{~m}$ surveys. "Threshold size for focal colony" is the size above which surveyed colonies were designated "focal" and below which colonies were designated "radial." "Maximum distance" is the distance up to which radial colonies were considered. 


\begin{tabular}{|c|c|c|c|c|}
\hline $\begin{array}{c}\text { Threshold size } \\
\text { for focal colony }\end{array}$ & $\begin{array}{c}\text { Maximum } \\
\text { distance }\end{array}$ & Slope & z value & p-value \\
\hline \hline \multirow{3}{*}{$15 \mathrm{~cm}$} & $0.50 \mathrm{~m}$ & -0.0064 & -0.46 & 0.65 \\
\cline { 2 - 5 } & $1.0 \mathrm{~m}$ & -0.0063 & -1.5 & 0.14 \\
\cline { 2 - 5 } & $2.0 \mathrm{~m}$ & -0.0034 & -3.6 & $<0.0005$ \\
\hline \multirow{3}{*}{$20 \mathrm{~cm}$} & $0.50 \mathrm{~m}$ & 0.047 & 1.2 & 0.23 \\
\cline { 2 - 5 } & $1.0 \mathrm{~m}$ & 0.00032 & 0.045 & 0.96 \\
\cline { 2 - 5 } & $2.0 \mathrm{~m}$ & -0.0016 & -1.09 & 0.27 \\
\hline
\end{tabular}

1 